\title{
"YouTube Has Changed Everything"? Music Faculty, Librarians, and Their Use and Perceptions of YouTube
}

\section{Kirstin Dougan}

\begin{abstract}
YouTube's accessibility, ease of use, and depth of content are strong lures for music students. But do music teaching faculty and librarians encourage this and do they use it in their own research, teaching, and work? This study surveyed over 9,000 music faculty and over 300 music librarians in the United States. It discovered that faculty rank is at times a factor in faculty use of YouTube for teaching and research - but not always in expected ways. It also found that faculty and librarians do not entirely share perspectives concerning the quality of YouTube's content, metadata, or copyright concerns.
\end{abstract}

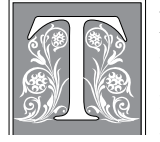

here are many contrasts to be found in YouTube, the world's largest and most popular video-sharing website: professional and amateur performances, high- and low-quality recordings, popular music and classical music, legal uploads and illegal uploads. The ability to immediately see and/ or hear different types of materials such as master classes (in which master performers conduct lessons with students in front of an audience), recitals, field recordings, interviews, tutorials, as well as current popular songs, makes YouTube an attractive source for the casual listener and serious music student alike. The increase of the cloud mentality (the ability and desire to store digital materials online and access anywhere), the pedagogical value of video, and music curricula that are evolving to include more popular and world musics and embrace participatory culture make YouTube a resource that academics, especially those in music and the performing arts, cannot ignore.

Although it has been documented that YouTube is much consulted by music students, no study has examined what value music teaching faculty and music librarians place on it and similar sites such as Vimeo for professional, not personal, use. ${ }^{1}$ This article reports the findings of a multi-institution survey of music teaching faculty and music librarians and attempts to answer the following broad research questions:

- How do teaching faculty members use YouTube in their teaching and research?

- How do music librarians use YouTube in their work?

- $\quad$ Are there differences in YouTube use/perceptions between faculty members at different points in their careers?

Kirstin Dougan is Music and Performing Arts Librarian at University of Illinois at Urbana-Champaign; e-mail: dougan@illinois.edu. The author wishes to acknowledge the Research and Publication Committee of the University of Illinois Library, which provided support for the completion of this research and to extend thanks to the ATLAS Survey staff, especially Dawn Owens-Nicholson, and the student assistants who compiled the 9,000 e-mail addresses. (C) 2014 Kirstin Dougan, Attribution-NonCommercial (http:// creativecommons.org/licenses/by-nc/3.0/) CC BY-NC 
- How do faculty member and music librarian perceptions of the usefulness of and concerns about You Tube differ?

In addition, this study also investigates narrower questions such as whether faculty approach YouTube much as they do their university's music library; whether faculty encourage students to use YouTube for posting or consuming content; whether faculty post their own material there; and whether librarians embrace YouTube as a way of supplementing their purchased collections. While this survey gathered data about YouTube use by faculty in subdisciplines such as music theory, ethnomusicology, conducting, and performance areas, discussion and analysis of those data will be reported in a separate article in the music literature.

\section{Background}

Since the invention of recording, music media formats have slowly but steadily shifted through numerous physical iterations (including wax cylinders, 78s, LPs, cassette tapes, and CDs) to online files both downloaded and streamed. The entire model of music distribution is in the process of changing due in large part to disintermediation. Whereas before, some content was only accessible in fragile formats or personal field recording collections, now artists can put their own music on a platform such as iTunes and sell directly to the consumer. Digital (online) music revenue in the United States reached $\$ 5.2$ billion in $2011 .^{2}$ It stands to reason that the "decoupling of musical content and its packaging" 3 would affect those researching and teaching music and how they interact with music. But how? With the advent of smartphones and cloud storage systems, individuals expect to have media content at their fingertips. Unfortunately, what this model does not currently allow for is the purchase, curation, and distribution of these materials by libraries. ${ }^{4}$ While the use of commercial online streaming products such as Naxos Music Library and Alexander Street Press's Classical Music Library may have dwarfed the use of physical media in some libraries, these tools may not yet wholly meet the needs of students, faculty, and librarians. ${ }^{5}$ Thus, students and faculty also use sources such as YouTube.

Older recording formats such as 78s and LPs still have value because of content that is not available elsewhere, sound quality, and liner notes. While YouTube is not by any means a form of preservation recording, it can increase access to many historic recordings, perhaps leading patrons to library holdings. CDs offer greater data storage and ease of use than LPs, but they are still trumped by the many affordances of online access. An additional consideration is that many libraries don't loan media via ILL. This means that many libraries duplicate media holdings so that their patrons will have access. In a related issue, libraries lack the ability to collect and circulate material released online-only, such as via iTunes or YouTube. End-user license agreements (EULAs) for services like iTunes explicitly state that any material downloaded is for personal use only. This has a direct impact on collection development. If libraries don't have these recordings in their collections, then scholars need to find them on their own, either by purchasing them or accessing them on sites like YouTube.

YouTube also enables musicians to be part of the participatory culture, ${ }^{6}$ allowing them to share their own compositions and performances. The performing arts are areas in which faculty are conceivably as likely to be using YouTube in their own production and research as in their teaching. There are examples of individuals who have learned to play an instrument (or at least a style of playing) by only watching YouTube videos. ${ }^{7}$ Changes in music curricula such as the inclusion of more popular music, more use of technology in the classroom, more students studying at a distance, including via MOOCs (massive open online courses) $^{8}$ mean tools like YouTube cannot be ignored by professors or librarians, given the potential implications on instruction and collection development. 


\section{Literature Review}

Academic music libraries have collected physical manifestations of sound recordings, in all formats, for decades. The "Survey of the State of Audio Collections in Academic Libraries," conducted by CLIR in 2004, found that:

These collections are of enormous value for research and teaching. These rare and often fragile recordings, however, are in triple jeopardy: They are frequently not described or inventoried; they are orphaned by obsolete playback equipment; and they lack clearly documented rights that allow use. Making these recordings available to students and scholars can be difficult and costly. As a result, these collections are often underused. ${ }^{9}$

Although these issues are more problematic for older formats and noncommercially released (that is to say, unique) recordings, even CDs face them. This includes the aforementioned challenge (or at times complete lack) of bibliographic control due to difficulties in cataloging these materials and the need for specialists to do so. Therefore, these items may remain in cataloging backlogs with minimal or no bibliographic access by patrons. The complexities involved in describing musical works in library catalogs also make searching for music in any form challenging to users. ${ }^{10}$

Newer formats also present challenges for libraries. Ongoing access to online digital media poses concerns related to file format migration and delivery over time. Copyright affects files' longevity in online environments such as YouTube, as files posted illegally are often removed without warning. Prellwitz and Nelson found that the "half-life" of videos in YouTube, at least for popular songs, ranges from nine to eighteen months. However, "There was never a time where no videos were available for any song in this collection," 11 and "Despite its use, although individual URLs come and go quite frequently, the music video persists, in aggregate, quite well in YouTube."12 But the situation for classical and noncommercial recordings is likely to be somewhat different from this study using popular songs-perhaps in their favor.

Burgess and Green's YouTube: Online Video and Participatory Culture offers a broad narrative of the culture and history surrounding YouTube as well as how it is being used by different audiences. ${ }^{13}$ Several publications focus on the use of YouTube as an educational tool. Rudolf and Frankel's book YouTube in Music Education talks about the attraction of YouTube and student use of it, as well as how YouTube works, copyright issues, and how to create videos for posting on YouTube. ${ }^{14}$ Articles by Mercer and Webb discuss using YouTube in the classroom. ${ }^{15}$ Draper talks both about how YouTube and other video-sharing sites have changed the music industry and how it has affected higher education. ${ }^{16}$

Although use of YouTube by particular subspecialties in music will be considered in depth in a follow-up article, some of the discussions in the literature are universal. For example, Hope Munro Smith's chapter “Global Connections via YouTube: Internet Video as a Teaching and Learning Tool" in Pop-Culture Pedagogy in the Music Classroom: Teaching Tools from American Idol to YouTube, focuses on using YouTube in the ethnomusicology classroom, but her insights can be more broadly applied. ${ }^{17}$ She asserts that YouTube is useful for illustrating key concepts as well as for providing specific musical examples from all genres, making lectures more engaging, and allowing students to post their own content.

Finally, Homenda's article "YouTube in Libraries"18 determined to what extent music libraries are using YouTube to post their own content. He found that the majority of libraries that are doing this are academic libraries and that tours are the predominant type of content they post. 


\section{Methodology}

In the spring semester of 2012, a two-part online survey, approved via the University of Illinois's IRB process, was sent by direct e-mail to 9,744 music faculty members and 331 music librarians at 197 departments, schools, colleges, and conservatories of music in the United States. The list of schools was devised by comparing the National Association of Schools of Music (NASM) membership list with the Music Library Association (MLA) membership list. The 168 schools on the NASM list that also had music librarians who are individual or sustaining members of MLA were included. Twenty-nine additional schools that had MLA-member librarians but were not NASM members were included to round out representation by type of school and geographic location.

Each music department (or school or college, and so on) website was searched for music faculty e-mail addresses. Nine schools on the original list of $197 \mathrm{did}$ not publish e-mail addresses for faculty on their websites and so were not included in the survey distribution for faculty, although librarians at those schools still received surveys. Adjunct and visiting faculty members as well as lecturers and performers in residence were included. Administrative staff and emeritus faculty were excluded. A total of 331 music librarians who are MLA members at the 197 schools were included. Any librarians at NASM schools who are not MLA members were not included. There were discrete surveys for teaching faculty and librarians. If a librarian was also included on the school's faculty list (for example, because s/he teaches a credit course) s/he was contacted only in his/her capacity as a librarian.

The ATLAS survey office on campus assisted with the construction of the survey and distributed it between April 18, 2012 and May 30, 2012. They also handled data cleanup and conducted data analysis using SPSS, in consultation with the author. Chi-square (frequency distributions), Levene's test (equality of variances), and ANOVA or t-tests (equality of means) were performed on those response categories with enough data to be calculable. The significances cited below are based on the ANOVA (for faculty rank and areas of faculty performance subspecialization) or t-tests (for areas of major faculty specialization or faculty vs. librarian comparisons) and will be reported as $p=X$ in all cases. While the questions in the survey used the terminology "video sharing sites," a catch-all term that was described as including YouTube and Vimeo, "YouTube" will be used throughout this article because it is the largest and most used by respondents.

\section{Findings}

\section{Faculty Response Profile}

Responses were received from 2,156 (22.5\%) of the 9,744 faculty members invited to

\begin{tabular}{|l|c|c|c|c|}
\hline \multicolumn{5}{|c|}{$\begin{array}{c}\text { TABLE 1 } \\
\text { Type of Institution }\end{array}$} \\
\hline & \multicolumn{2}{|c|}{ Faculty } & \multicolumn{2}{c|}{ Librarians } \\
\hline & Number & $\%$ & Number & $\%$ \\
\hline Conservatory & 183 & 8.5 & 23 & 10.6 \\
\hline Department of Music & 638 & 29.6 & 71 & 32.6 \\
\hline School of Music & 1,087 & 50.4 & 77 & 35.3 \\
\hline College of Music & 170 & 7.9 & 20 & 9.2 \\
\hline Something Else & 76 & 3.5 & 26 & 12.0 \\
\hline Total & $\mathbf{2 , 1 5 4}$ & $\mathbf{1 0 0 . 0}$ & $\mathbf{2 1 7}$ & $\mathbf{1 0 0 . 0}$ \\
\hline
\end{tabular}


take the survey. Of the 331 librarians invited to take the survey, 217 (65.6\%) responded. Respondents predominantly come from schools or departments of music (see table 1).

Faculty were asked to identify their rank (see figure 1). The largest group of respondents was full professors (29\%), followed by adjunct/visiting/lecturers (26\%). There are a high number of adjunct/lecturer/visiting positions in music, due in part to the fact that that many are active performers as well as teachers. Examples in the "Something else" category included "Assistant faculty associate," "Postdoctoral fellow," and "Academic specialist."

Faculty members were asked whether their institutions use YouTube or another tool in an official capacity to post performances, master classes, recruiting materials, or other materials. More than a third (38\%) answered yes, 30 percent answered no, and another 30 percent said they did not know. Schools that use these tools (primarily YouTube and/or their own websites) post performances (44\%), recruiting materials (35\%), master classes (18\%), interviews $(16 \%)$, other $(5 \%)$.

A full third (33\%) of faculty respondents are posting their own content to YouTube or similar sites. Of the respondents who post, 82 percent are using YouTube, 36 percent are posting to their own website, 15 percent are using "another site," 13 percent are using Vimeo, and 5 percent are using MySpace (they could choose more than one). The majority of faculty uploads are performances (25\%), while an additional 6 percent each are master classes, interviews, and recruiting materials. Eight percent of faculty also post things such as auditions, an "etude and excerpt project," lectures, student projects, student practice teaching, and one respondent replied, "I write music for videos specifically made for YouTube."

\section{Librarian Response Profile}

Librarian respondents had anywhere from less than one year to 40 years of experi-

\begin{tabular}{|l|c|}
\hline \multicolumn{2}{|c|}{ TABLE 2} \\
Libraries/ Online Streaming Media Subscriptions \\
\hline & $\begin{array}{c}\text { \% of Respondents } \\
\text { Who Subscribe }\end{array}$ \\
\hline Naxos Music Library & $89 \%$ \\
\hline DRAM & $56 \%$ \\
\hline Classical Music Library (ASP) & $59 \%$ \\
\hline Opera in Video (ASP) & $44 \%$ \\
\hline Jazz Music Library (ASP) & $41 \%$ \\
\hline American Song (ASP) & $41 \%$ \\
\hline Contemporary World Music (ASP) & $34 \%$ \\
\hline
\end{tabular}
ence, with a mean of 15 years. Librarians use YouTube in many facets of their work, including Reference (79\%), Collection Development (70\%), Cataloging (49\%), Instruction $(69 \%)$, as well as to post about their library (47\%).

For context, libraries frequently subscribe to one or more commercial audio or video streaming resources, as seen in table 2 .

Only 3 percent of librarian 
respondents stated that their library did not subscribe to any commercial streaming services. The oldest of these resources has existed for eight years, and they are seen as legitimate extensions to libraries' physical collections. Some libraries are spending much of their media collections budgets on these tools rather than on physical media, due to patron needs and preferences and the library's budget. Librarians feel that sites like YouTube can be seen as an extension of their library collections to a small extent $(64 \%)$ or a large extent $(20 \%)$, with 16 percent saying that they do not see these sites as an extension of their collection.

\section{Librarian Use of YouTube}

The most frequent uses of YouTube by librarians, ranked by totaling the responses in the "very often" or "often" categories, are Instruction, Collection Development, Cataloging (tied with) Posting about Your Library, and finally, Reference. Instruction has the most "very oftens" and fewest "nevers" while Reference has fewest "very oftens." While both Cataloging and Posting about Your Library have more "very oftens" than Reference, Posting about Your Library and Cataloging are overall the least performed activities using YouTube. However, some catalogers responded that YouTube is invaluable in their work for identifying pieces from student recitals. Other uses cited by librarians include posting vodcasts of library instruction sessions, posting virtual tours of the library, and marketing the library as described below.

We modify existing YouTube videos and use them in-house only on a[n] HDTV information screen at our service desk in the music library. The videos are shortened to 30 seconds to 1 minute, and captions are added to give data about composers, performers, etc., and library collection information such as call numbers for CDs, DVDs, etc. featuring the artists found in the video clip.

\section{Faculty Use of YouTube}

Faculty members were asked about their search habits in YouTube and could choose more than one option. Responses are summarized in figure 2.

Examples of "Something else" include things not necessarily available from library sources, such as "archival news footage of historical significance," "cultural background

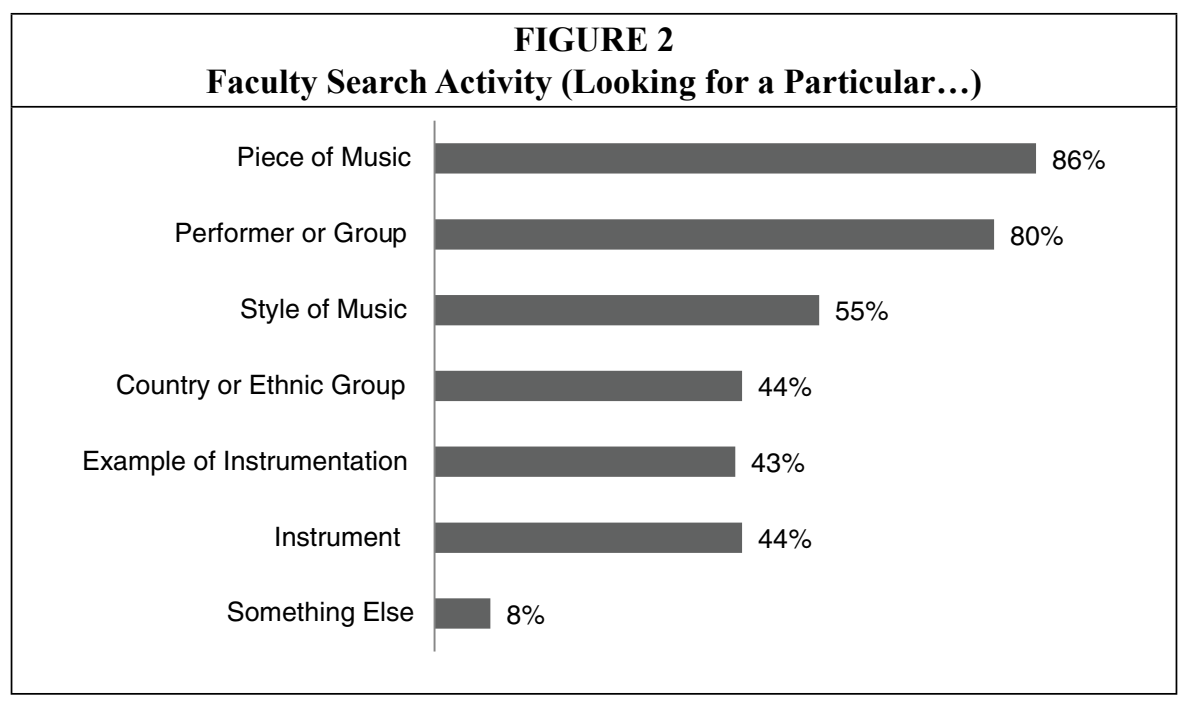




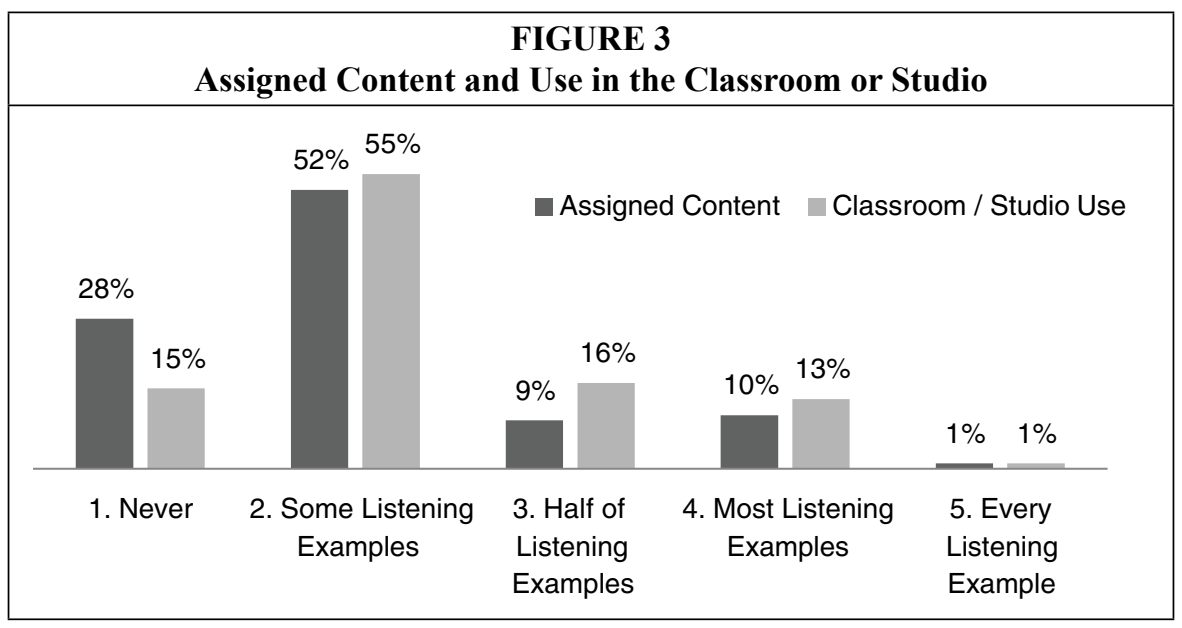

information," "examples of classroom music lessons," "foreign language pronunciation," "lectures," "music therapy examples," and "world pop/jazz before 1940," to name only a few.

Faculty members are equally likely to use YouTube when an item isn't commercially available as when the item isn't available at their library. More than three quarters $(77 \%)$ of respondents will use YouTube "often" or "very often" if a recording is not commercially available or is not available from the library. Fewer than 2 percent of respondents will never use YouTube in these circumstances.

\section{Teaching with YouTube}

The majority of faculty respondents use YouTube to supply at least some listening examples in the classroom/studio and for assigned content (like course reserves) (see figure 3). One librarian commented that their current library systems make it difficult or impossible to provide streaming course reserves, and so faculty rely on YouTube instead. Faculty are overall more likely to use YouTube in the classroom or studio ( 2.30 mean) than to assign content from it (2.08 mean), (with 1 = "never" and $5=$ "every listening example").

\section{Student Posting to YouTube and Citing YouTube as a Source}

Only 15 percent of faculty respondents have required students to post examples of their own work (rehearsals, projects, classroom teaching, and so on) to YouTube. Of the faculty who assign papers, 55 percent allow students to cite YouTube in some assignments, 20 percent never let students cite it, and 8.5 percent allow it in every paper. Associate professors are the least likely to let their students cite YouTube $(25 \%$ say "never"), followed closely by assistant and full professors (only 19\% of whom say "never"). Adjuncts/lecturers are the most likely to let students cite YouTube (12\% allow for every assignment compared to only $7 \%$ of full professors). The mean for all faculty is 2.35 ( $1=$ "never" and $5=$ "allow in every assignment"). To aid this activity, some libraries even include YouTube examples in their citation guides. Although more than half of faculty let their students cite YouTube, only 6 percent of faculty have cited YouTube in a peer-reviewed article of their own. A scan of the literature shows that scholars have cited YouTube clips in articles published in peer-reviewed music journals such as American Music, ARSC Journal, Asian Music, Choral Journal, Ethnomusicology, Journal of American Folklore, Journal of Singing, Music Theory Spectrum, and many more. Sixty percent have never cited YouTube, 31 percent said this does 


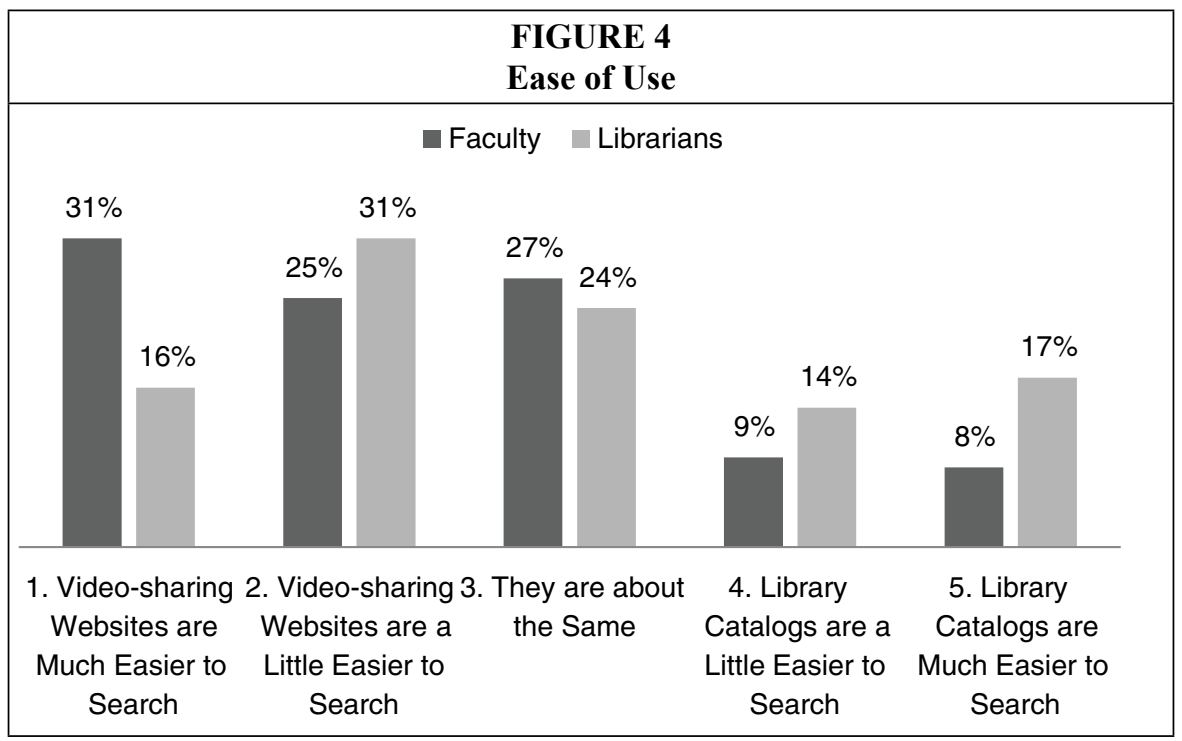

not apply to them (presumably they do not author peer-reviewed articles), and 3 percent did not respond.

\section{What Draws Faculty to YouTube?}

\section{Perceived Ease of Use}

Faculty and librarians were asked to compare the relative ease of use of YouTube and library catalogs, as seen in figure 4 .

The overall faculty mean for this question is 2.38 and the librarian mean is 2.84, where 5 is "library catalogs are much easier to search" and 1 is "YouTube is much easier to search," which is a significant difference. Higher-ranked professors leaned slightly toward the middle of the spectrum. Full professor mean was 2.54 (between "YouTube is a little easier," and "they are about the same"), adjuncts/visiting/lecturers' mean response was 2.23, which is closer to "YouTube is a little easier to search," and assistant and associate professors fell in between.

\section{Convenience Factor}

Over half $(51 \%)$ of faculty say YouTube is much more convenient than library collections, and another 26 percent say YouTube is a little more convenient than library collections. Only 14 percent say YouTube and library collections offer about same convenience factor, and a mere 9 percent say library collections are either a little or much more convenient than YouTube. In one of the few questions where rank followed the expected pattern, more highly ranked faculty members said that the library was more convenient than YouTube, with the overall mean response at 1.83 (with YouTube $=1$ and the library =5). However, even full professors' mean response was 2.01 or "YouTube is a little more convenient than the library."

\section{Comparing Faculty and Librarian Perceptions}

To establish a context for how librarians perceived faculty use of YouTube and the library, librarians were asked about their perception of student use of YouTube and library collections. Not surprisingly, librarians think students are much more likely to use YouTube than library collections, as seen in figure 5 . 


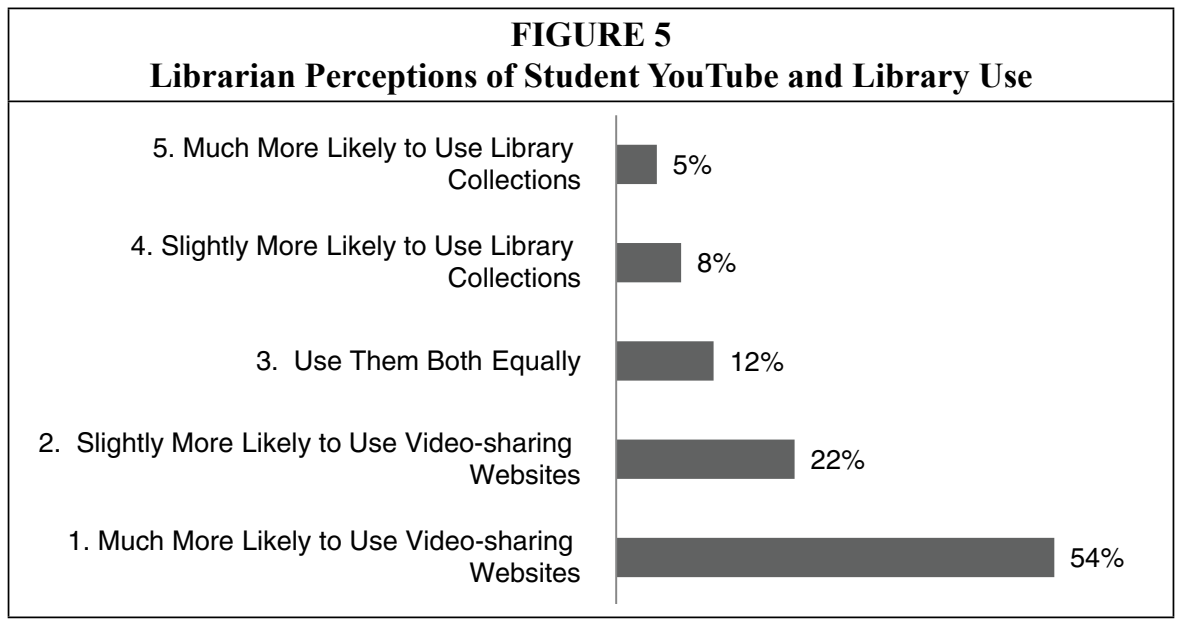

Librarians were then asked how likely they thought faculty were to use YouTube or library collections to find recordings, and faculty were asked how likely they were to use YouTube or library collections to find recordings, as seen in figure 6.

The librarian mean (measuring perception of faculty use) was 3.66, while the mean response for all faculty was $2.62(1=$ "much more likely to use YouTube" and $5=$ "more likely to use library collections"). Full professors are most likely to use library collections, with 19 percent of full professors at "much more likely to use library collections," (2.87 mean), and 32 percent of assistant professors and 38 percent of adjunct/visiting faculty "much more likely to use YouTube" (2.37 mean).

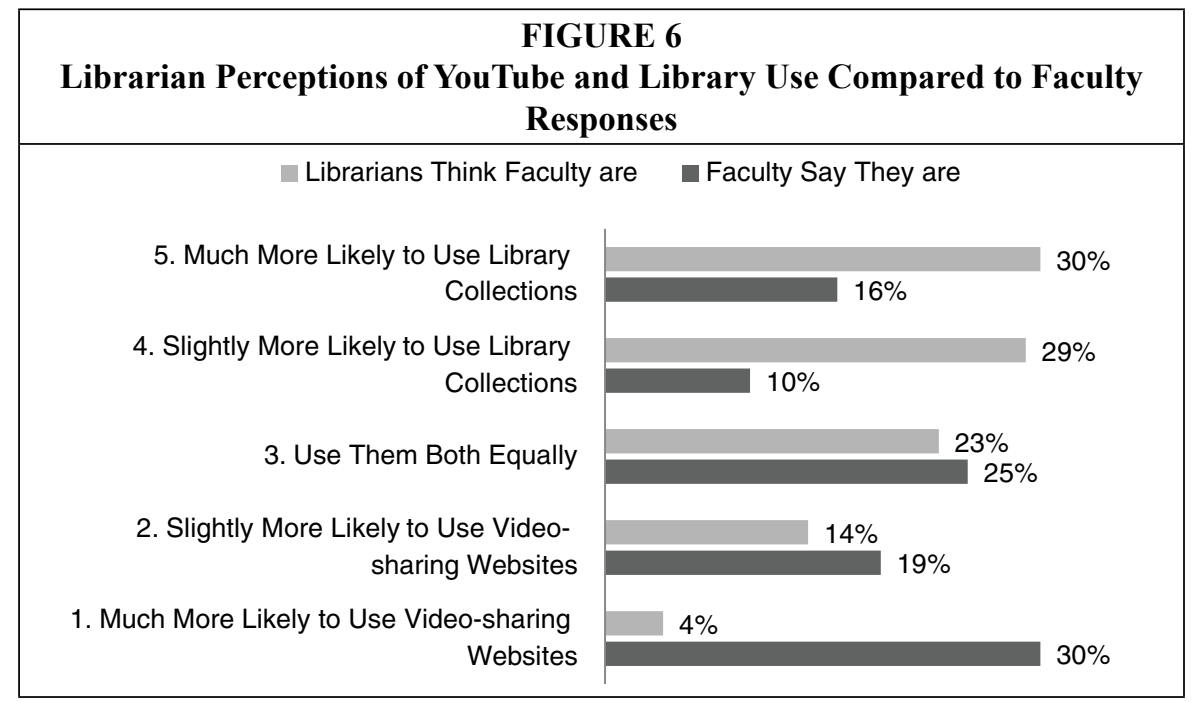

\section{Comparing Faculty's and Librarians' Concerns}

Quality of Content

Faculty and librarians were asked about their level of concern with the quality of recordings on YouTube, as seen in figure 7. The question was intentionally broad, not specifying recording quality (such as fidelity) or performance quality. 


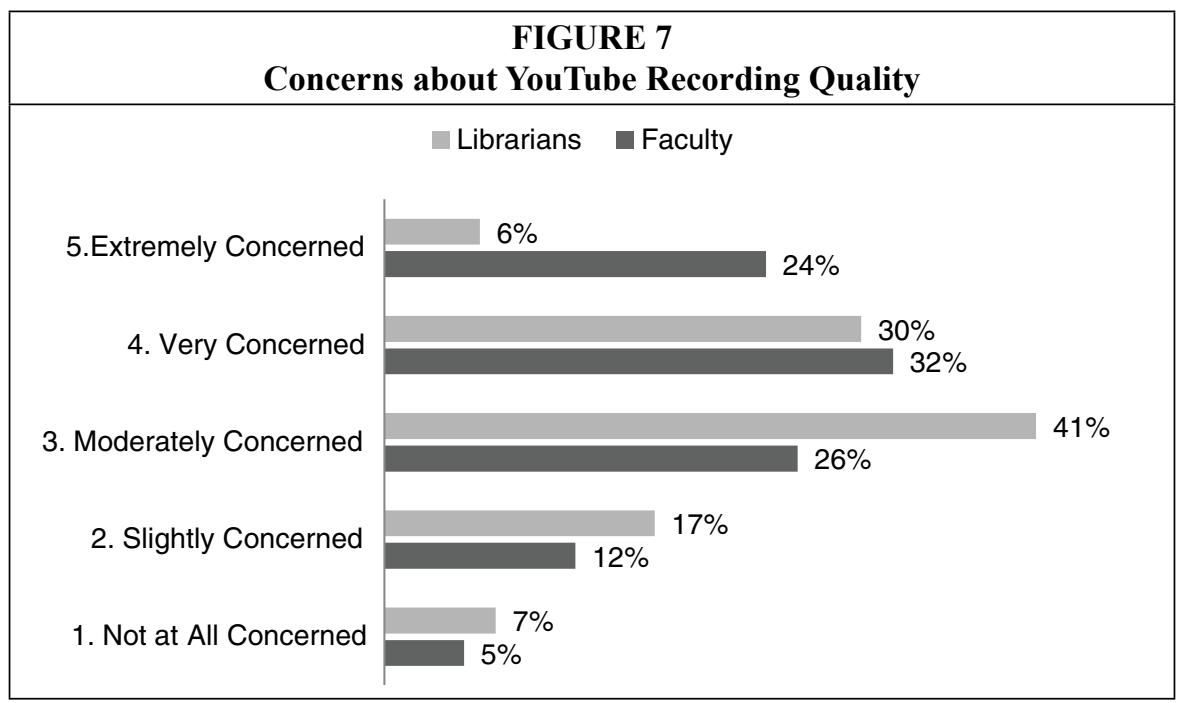

This issue is a clear concern for faculty (3.58 mean), more so than for librarians (3.10 mean) ( $1=$ "not at all concerned" and $5=$ "extremely concerned"). Combining "extremely" and "very concerned" responses accounts for 56 percent of faculty and 36 percent of librarians. Adjuncts/visiting/lecturers are the least concerned about quality, full professors are the next least concerned, with associate professors next and assistant professors the most concerned (29\% "extremely concerned" vs. $23 \%$ for full professors). Comments show that both librarians and faculty are afraid that students' heavy reliance on YouTube means they might overlook good (better) content in the library. The longevity and reliability of content in YouTube is another big concern for librarians and faculty.

\section{Accuracy of Metadata}

Faculty and librarians were asked about their level of concern with the "quality of data describing the recordings" on YouTube, as seen in figure 8.

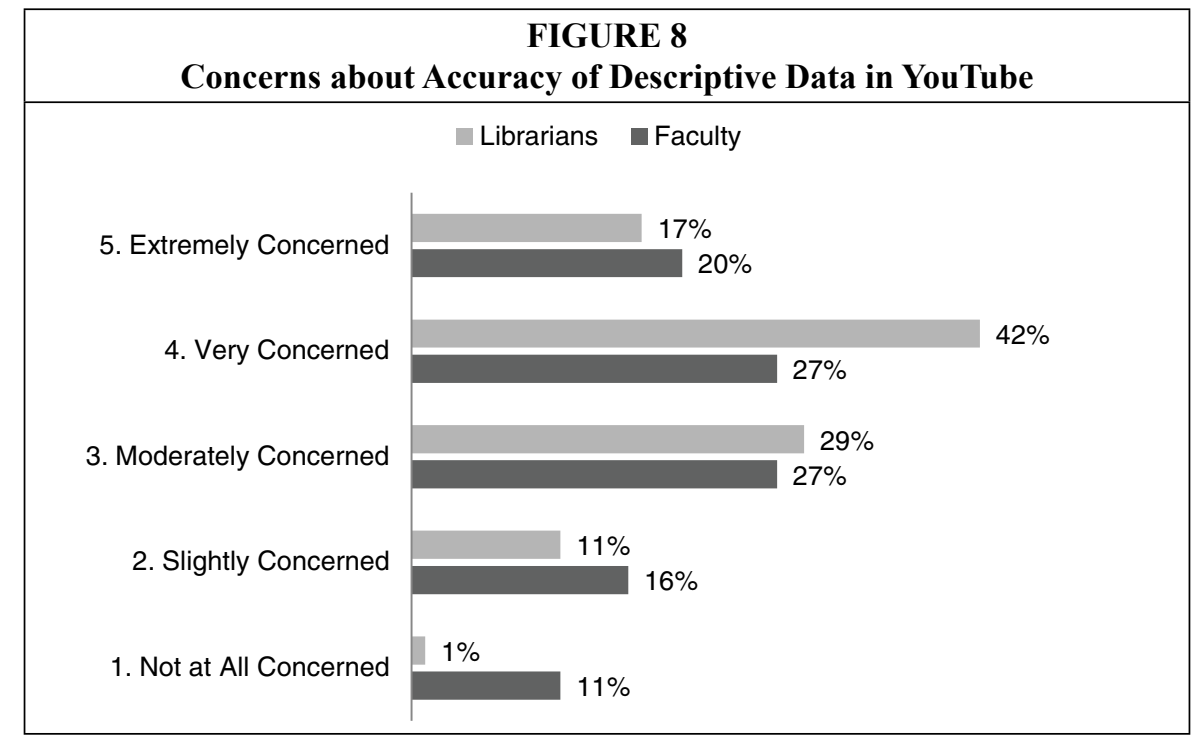


More faculty than librarians are not at all concerned about data accuracy levels, but overall it is still an area of concern. Combining "extremely" and "very concerned" responses accounts for 47 percent of faculty and 59 percent of librarians. The faculty mean is 3.29 and librarian mean is 3.63 , with $1=$ "not at all concerned" and $5=$ "extremely concerned."

\section{Concerns about Copyright}

Faculty and librarians were asked how concerned they were with copyright issues related to YouTube, as seen in figure 9. This is the only faculty question in which neither rank nor area of specialty were significant factors. Faculty mean is 2.93 and librarians' is 3.31, with $1=$ "not at all concerned" and $5=$ "extremely concerned."

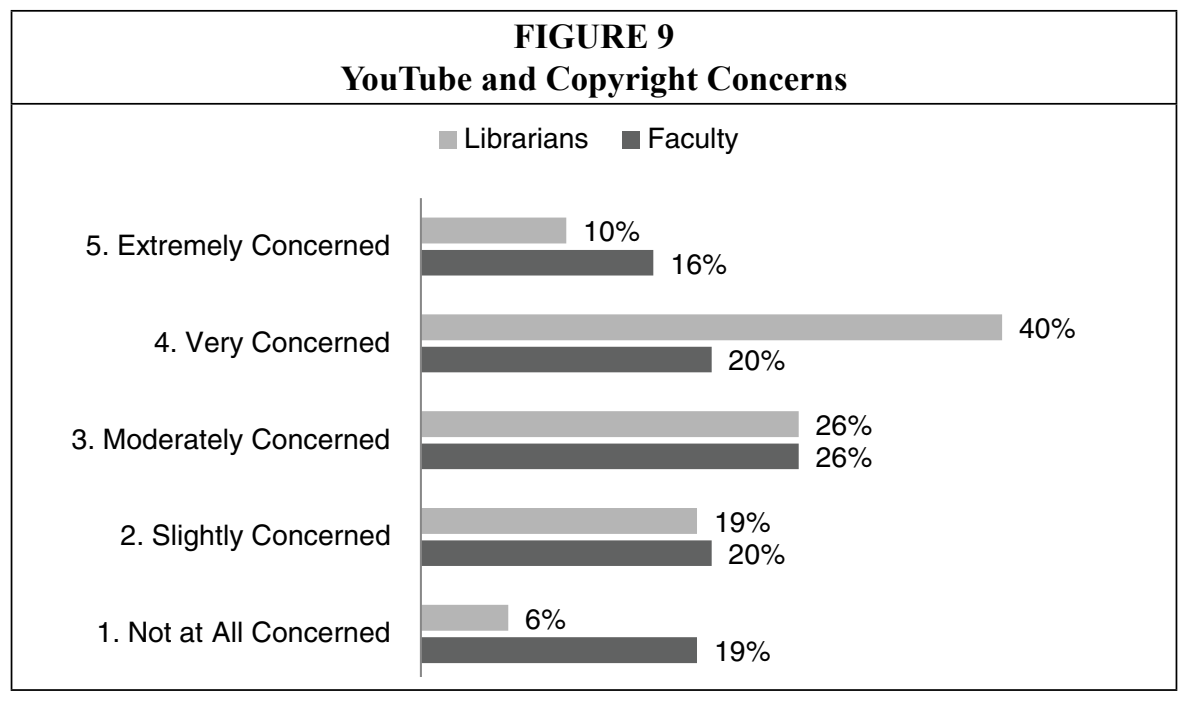

Although faculty responses in the "extremely concerned" category outweigh librarians' responses 16 percent to 10 percent, more than three times as many faculty responses were "not at all concerned" (19\% vs. $6 \%$ of librarians' responses). Combining "extremely" and "very concerned" responses accounts for 36 percent of faculty and 50 percent of librarians.

In every comparison of librarian and faculty like question pairs, job role is statistically significant, meaning an individual's job was a factor in how s/he answered. Faculty responses tend toward the extremes (with answers often at "extremely" or "not at all"), while librarians tend to have more moderate responses.

\section{Discussion}

Even though they themselves are using YouTube in their work, librarians would like to think that the music faculty they serve are using library collections more than they actually are. In reality, as this study suggests, faculty use YouTube both in teaching and in their own research, in addition to posting their own content there. It is reasonable to surmise that the trends found with music faculty are generalizable to the larger academic population, as nonmusic faculty are likely less aware of what music resources are available to them via the library. While it is clear from the responses and comments that, while faculty overall still value library collections and have some concerns about YouTube, they use YouTube despite their reservations, in some cases 


\begin{tabular}{|l|c|c|c|c|c|}
\hline \multicolumn{7}{|c|}{ LAbrarian and Faculty Mean Comparisons } \\
\hline Question & $\begin{array}{c}\text { Primary } \\
\text { Role }\end{array}$ & Number & Mean & $\begin{array}{c}\text { Std. } \\
\text { Deviation }\end{array}$ & $\begin{array}{c}\text { Std. Error } \\
\text { Mean }\end{array}$ \\
\hline $\begin{array}{l}\text { How concerned are you about: } \\
\text { The quality of the recordings? }\end{array}$ & $\begin{array}{c}\text { Teaching } \\
\text { Faculty }\end{array}$ & 2,048 & 3.58 & 1.129 & 0.025 \\
\cline { 2 - 6 } & Librarian & 213 & 3.1 & 0.983 & 0.067 \\
\hline $\begin{array}{l}\text { How concerned are you about: } \\
\text { The accuracy of the data } \\
\text { describing the recordings? }\end{array}$ & $\begin{array}{c}\text { Teaching } \\
\text { Faculty }\end{array}$ & 2,036 & 3.29 & 1.254 & 0.028 \\
\cline { 2 - 6 } & Librarian & 216 & 3.63 & 0.925 & 0.063 \\
\hline $\begin{array}{l}\text { How concerned are you about: } \\
\text { Copyright issues? }\end{array}$ & $\begin{array}{c}\text { Teaching } \\
\text { Faculty }\end{array}$ & 2,047 & 2.93 & 1.334 & 0.029 \\
\cline { 2 - 6 } & Librarian & 215 & 3.31 & 1.063 & 0.072 \\
\hline $\begin{array}{l}\text { Compared to your institution's } \\
\text { online library catalog, how easy } \\
\text { is it to search video sharing } \\
\text { websites? }\end{array}$ & $\begin{array}{c}\text { Teaching } \\
\text { Faculty }\end{array}$ & 1,908 & 2.38 & 1.239 & 0.028 \\
\cline { 2 - 6 } & Librarian & 200 & 2.84 & 1.313 & 0.093 \\
\hline
\end{tabular}

extensively. And although faculty are concerned that students may overlook quality content in the library, faculty in many cases contribute to students' use of YouTube by using examples in class and assigning examples from it.

The sheer amount and wide variety of content available in YouTube far surpasses that which can be found in most academic libraries. The convenience factor of YouTube is also a huge draw for both faculty and students-it's always accessible, while the library is not. However, online availability isn't the only factor-all but 2 percent of the responding libraries subscribe to at least one commercial online audio tool and many offer some method of online audio reserves service. Therefore, the fact that many faculty and students use YouTube (at times instead of library-supplied tools) is one that cannot be ignored.

Library collections, both physical and online, suffer from visibility, usability, and accessibility issues. Patrons have to be taught about these collections and resources, often subscription tools require additional steps to be accessed from off-campus, and some libraries do not circulate physical media. Library catalogs (and even now web scale discovery layers) frequently do not accommodate music materials well. Cataloging backlogs of music materials only exacerbate this. Even though some faculty advocate for how much better/more powerful library catalogs are than tools like YouTube, faculty overwhelming find YouTube to be easier to use than library catalogs.

Approaching this study, the author hypothesized that there would be observable differences between faculty at different ranks, with adjuncts being more accepting of YouTube, and full professors being almost totally against the use of YouTube. Rank is a factor in almost all of the questions, but not always in the way expected; that is, full professors were not consistently on the end of the spectrum farthest from YouTube. Higher ranked faculty members are more likely to respond that the library is more convenient than YouTube, and that they are more likely to use library collections than YouTube. Because adjuncts and lecturers often work at multiple institutions and may not be on campus as frequently and/or may not want the hassle of learning multiple library systems, it makes sense that YouTube may appeal to them. Since rank was consistently a significant factor in all survey answers (except concern over copyright), 
it is apparent that faculty use and perceptions of resources such as YouTube will shift over time, as today's assistant professors eventually become full professors. At the same time, however, changes in tenure systems are leading to an increase in adjunct positions in many departments. That, coupled with the current trend of growth in online learning environments in higher education, means libraries will need to cater to a professoriate and student body that is more dispersed.

An apt analogy for the currently evolving relationship between YouTube and library collections is that of the more settled relationship between Wikipedia and tools such as Encyclopedia Britannica. Initially, academics were concerned that students would completely eschew trusted library resources in favor of Wikipedia. However, over time, librarians have developed successful strategies for teaching patrons when to use Wikipedia and when Encyclopedia Britannica is more appropriate. Similarly, YouTube can and does have a rightful place in the academic's toolkit, but it has to be in the correct context. This may vary based on the library's collections and the researcher's needs.

The implications of the widespread use of YouTube and the findings of this study are much the same for music and nonmusic librarians. First and foremost, librarians need to know their patrons and the specific needs of those patrons. Local surveys of faculty and students can determine whether music and selected nonmusic faculty and students know about relevant physical and online library collections, whether these collections meet their research needs, and whether faculty know about existing course reserves services from the library. The results of such surveys can lead to targeted marketing and collection development efforts. Second, librarians need to make it as easy as possible for patrons to find and use collections. Where possible, libraries should import catalog records for their electronic holdings just as they do for physical CDs and DVDs. Librarians can continue to work with local programmers and vendors to create search and discovery platforms that work for all materials. Media materials should circulate. Third, course reserves systems should be as simple as possible for faculty to use. This includes not only creating e-reserves based on the library's physical collection, but encouraging faculty to include permalinks from Naxos or ASP products, and potentially to allow linking to YouTube tracks from legitimate sources (such as channels created by artists and performers for their own content). Librarians can also offer instruction to faculty in how to create playlists within tools such as Naxos and ASP for use in the classroom or for class listening assignments.

Fourth, in addition to instructing patrons in the best ways to use YouTube and how to find quality content there, librarians can offer guidance for faculty and students in how to create metadata when uploading their own materials. Finally, librarians must educate both themselves and their patrons about copyright and fair use issues surrounding music media (including posting to and linking from YouTube). In all of these areas, music librarians should to reach out to nonmusic librarians, faculty, and students where appropriate, since those individuals will generally have less knowledge of the physical and licensed music collections available to them, as well as of copyright and other issues surrounding YouTube and its use.

\section{Limitations of the Study}

One potential problem with this study is that no distinction between the visual and audio aspects of YouTube was made (content there can be solely audio, or audio with video). However, some respondents felt that this was a key distinction. An adjunct professor in jazz studies said, "I'm concerned that music continues to become less of a sound medium, and more of a visual medium." And a full professor in ethnomusicology wrote, "Several of your questions were not broad enough to understand relevant alternative data. You used the term 'listening' as applied to 'video.' There is a 
vast difference between use of these two." This is understood, but the researcher felt it better to combine the two elements and allow respondents to interpret a question as they wished, rather than have many more overly specific questions, which would have made the survey much longer.

Another possible concern is that some faculty respondents may have confused "video-sharing websites" with institutional course reserve systems or Blackboard, even though the phrase was defined to mean tools such as YouTube and Vimeo. Also, the survey did not ask faculty specifically about use of their libraries' subscription streaming media content. Instead, questions said "library collections," intending all formats. The survey could have clarified by using terms like "physical" or "electronic," but hopefully the initial definition given in the survey for "video-sharing websites" made it clear that it didn't include library-provided resources.

\section{Further Research}

As mentioned earlier, additional data from this survey describing differences in YouTube use between music faculty in different subspecialties will be published at a future date. Other studies should seek to investigate more fully YouTube use by particular specialties, such as ethnomusicology and jazz, to inform librarians how those groups are using YouTube. Also stated earlier is the need for local research that would educate librarians about the extent to which their patrons use the library's physical and licensed collections and YouTube. Content analysis exploring the scope and depth of legitimate recordings relevant to particular areas of music included in YouTube could provide a rich set of data for librarians and music researchers alike. The information from all of these potential studies could support collection development practices as well as enable libraries to meet their patrons' needs through collections and instruction.

\section{Conclusion}

In an era of flat or shrinking budgets, can librarians' carefully curated collections compete with the accessibility, immediacy, variety, and vastness of YouTube? Disintermediation is a current trend not only in publishing as discussed above, but also in libraries. The library has traditionally been the middleman, building collections using a "just in case" model (but now shifting toward patron-driven acquisition to a greater degree) and providing content to patrons. However, patrons may no longer embrace this model and may want to play the primary role in obtaining and managing their own content. This also means that faculty can and do bypass the library when providing content to their students. In many cases, participatory culture means faculty and students are themselves content creators, especially in areas like the arts. Libraries cannot let the future of their collections be permanently hampered by changing music distribution models and copyright and licensing issues. Finally, the future of education, not just music education, with Massive Open Online Courses (MOOCs) now on the scene, ${ }^{19}$ means libraries will have to think beyond their physical walls in providing materials to students and faculty. However, copyright issues in MOOCs, which can be quite challenging for standard course materials, are even more complex for music. Exploring these issues is well beyond the scope of this study, but it bears further consideration in the research.

\section{Notes}

1. Kirstin Dougan, "Information Seeking Behaviors of Music Students," Reference Services Review 40, no. 4 (Nov. 2012): 558-73.

2. International Federation of the Phonographic Industry, "IFPI Publishes Digital Music Report 2012," available online at www.ifpi.org/content/section_resources/dmr2012.html [accessed 13 
December 2012].

3. Ibid.

4. Jeremy Morris, "Sounds in the Cloud: Cloud Computing and the Digital Music Commodity," First Monday 16, no. 5 (Apr. 2011), available online at http://firstmonday.org/htbin/cgiwrap/ bin/ojs/index.php/fm/article/view/3391/2917 [accessed 13 December 2012]; D.J. Hoek, "The Download Dilemma: The Demise of the Compact Disc Signals an Uncertain Future for Library Sound Recording Collections," American Libraries 40, no. 8/9 (2009): 54-57.

5. James Procell, "Trends in Patron Use of Physical Media Materials and Subscription Online Media Databases at the University of Louisville: A Ten-Year Study," Music Reference Services Quarterly 15, no. 4 (2012): 231-39.

6. Paul Draper, "How Online Social Networks Are Redefining Knowledge, Power, 21st Century Music-Making and Higher Education," Journal of Music Research Online 1 (2009): 1-20, available online at www.jmro.org.au/index.php/mca2/article/view/19 [accessed 13 December 2012].

7. “Usman Riaz and Preston Reed: A Young Guitarist Meets His Hero," TEDTalks, available online at www.ted.com/talks/lang/en/usman_riaz_and_preston_reed_a_young_guitarist_meets_ his_hero.html [accessed 13 December 2012)].

8. Music and Technoculture, eds. René T.A. Lysloff and Leslie C. Gay, Jr. (Middletown, Conn.: Wesleyan University Press, 2003).

9. Abby Smith, David Randal Allen, and Karen Allen, "Survey of the State of Audio Collections in Academic Libraries, Executive Summary," Council on Library and Information Resources, (August 2004), available online at www.clir.org/pubs/reports/pub128/sum128.html [accessed 13 December 2012].

10. Dougan, "Information Seeking Behaviors of Music Students," 565.

11. Matthias Prellwitz and Michael L. Nelson, "Music Video Redundancy and Half-life in YouTube," Research and Advanced Technology for Digital Libraries. Proceedings International Conference on Theory and Practice of Digital Libraries (TPDL 2011): 147.

12. Ibid., 150.

13. Jean Burgess and Joshua Green, YouTube: Online Video and Participatory Culture (Malden, Mass.: Polity Press, 2009).

14. Thomas E. Rudolph and James Frankel, YouTube in Music Education (New York, N.Y.: Hal Leonard Books, 2009).

15. Andrew Mercer, "The Educational Uses of YouTube," Canadian Music Educator 52, no. 3 (2011): 42-43; Michael Webb, "Music Analysis Down the (You)Tube? Exploring the Potential of Cross-media Listening for the Music Classroom," British Journal of Music Education 24, no. 2 (July 2007): 147-64; Michael Webb, “Re Viewing Listening: 'Clip Culture' and Cross-modal Learning in the Music Classroom," International Journal of Music Education 28, no. 4 (Nov.2010): 313-40.

16. Draper, "How Online Social Networks Are Redefining Knowledge," 1-20.

17. Hope Munro Smith, "Global Connections via YouTube: Internet Video as a Teaching and Learning Tool," Pop-Culture Pedagogy in the Music Classroom: Teaching Tools from American Idol to YouTube, ed. Nicole Biamonte (Lanham, Md.: Scarecrow Press, 2011).

18. Nick Homenda, "Music Libraries on YouTube," Music Reference Services Quarterly 14, no. 1/2 (2011): 30-45.

19. Jeffrey R. Young, "American Council on Education May Recommend Some Course Offerings for College Credit," Chronicle of Higher Education (Nov. 13, 2012), available online at http:// chronicle.com/article/MOOCs-Take-a-Major-Step/135750/ [accessed 13 December 2012]. 